\title{
A survey of consumer attitude towards nutrition and health statements on food labels in South Australia
}

\author{
Malcolm D. Riley ${ }^{1}$, Jane Bowen ${ }^{1}$, Debra Krause ${ }^{2}$, Darren Jones ${ }^{3}$, Welma Stonehouse ${ }^{1}$ \\ ${ }^{1}$ CSIRO Health and Biosecurity, South Australia Health and Medical Research Institute, \\ Adelaide, 5000, South Australia; ${ }^{2}$ CSIRO Agriculture and Food, Werribee, Victoria, Australia; \\ ${ }^{3}$ CSIRO Information Management and Technology, Urrbrae, 5001, South Australia
}

Corresponding author: Malcolm D. Riley, PhD, CSIRO Health and Biosecurity, PO Box 11060, Adelaide, South Australia, 5001

Submission Date: September 27, 2016, Accepted Date: December 27, 2016, Publication Date: December 30,2016

Citation: Riley M.D., Bowen J., Krause D., Jones D., Stonehouse W.. A survey of consumer attitude towards nutrition and health statements on food labels in South Australia. Functional Foods in Health and Disease 2016; 6(12):809-821

\begin{abstract}
Background: For many decades, Australia has required a Nutrient Information Panel to be included on food packaging, usually on the back of products. Recently, two regulated, voluntary systems were introduced for use on food packaging in Australia: the Health Star Rating system and nutrient content and health claims. Nonetheless, the scope and potential for these new initiatives to achieve their purpose is partly depdendant on their perception by consumers. This report describes the results of a population based survey of South Australian adults about how various elements of food labels are used to inform their purchase decisions.

Methods: A survey was conducted using a random stratified sampling technique in people aged 15 years and older in the Australian state of South Australia. All surveys were administered faceto-face to 3005 people between September 2015 and December 2015. Data was weighted by the inverse of the individual's probability of selection, as well as the response rate in metropolitan and country regions and then reweighted to benchmarks from the June 2014 Estimated Resident Population calculated by the Australian Bureau of Statistics.
\end{abstract}

Results: The response rate for the survey was 57.3\%. Most respondents to the survey rated their own dietary intake as 'healthy' $(61.5 \%)$ or 'extremely healthy' $(9.1 \%)$. Aside from price, country of origin was nominated as the most important information on the food label of a food bought for the first time (by 35.0\%), followed by the ingredient list (21.6\%) and claims about nutrition (20.9\%). The response to this question was markedly different by age group, with almost half $(48.3 \%)$ of those aged 55 years or over considering that country of origin was the most important information to look for. For the youngest age group (15-34 yrs), 28.4\% considered the ingredient list was the most important information, $26.5 \%$ considered claims about nutrition to be most important, and $22.2 \%$ considered country of origin to be the most important information on the food label. The Nutrition Information Panel was used to guide the purchase decision for a new 
breakfast cereal by more than half of respondents (50.8\%), while a statement on the front of the pack about how the food effects health was used to guide the purchase decision of only $8.9 \%$. While only $22.1 \%$ disagreed (16.4\% disagreed somewhat, $5.7 \%$ disagreed completely) with the statement that 'the Nutrient Information Panel on food packaging is a trustworthy source of information,' almost double the amount of subjects at $44.0 \%$ disagreed $(36.1 \%$ disagreed somewhat, $17.9 \%$ disagreed completely) that 'statements about health on food packaging are a trustworthy source of information.'

Conclusion: For South Australian adults, statements about health benefits of food on food packaging are viewed with much greater suspicion than the nutrient information panel. Attitudes towards food packaging varied more by age group than by sex of the respondent. For an unfamiliar food, country of origin is considered the most important information on food packaging by more than a third of adults.

Keywords: Food packaging, Nutrition label, Front of Pack, Health Star, South Australia

\section{BACKGROUND:}

Food packaging provides an opportunity to communicate with potential purchasers as they reach their decision to purchase particular food products (i.e. at point of sale). Some elements on a food label are required by law, while other elements are optional but closely regulated. In Australia, as in other places, it is illegal to include information on packaging that is false or misleading. A body of research [1] has been focused on what type of labelling can assist consumers to make healthier food choices. A number of studies $[2,3,4,5]$ have compared food labels for their ability to be used by consumers to accurately rank foods within a category according to their health benefit. In general, these studies have indicated that evaluative labels (labels that provide an overall rating, such as traffic lights) better enable people to complete this task than reductive labels (labels that provide quantitative measures of one or more nutrients such as salt or sugar content). However, these studies are often undertaken in an experimental setting that sets an explicit task related to cognition, rather than exploring behaviour in a purchasing situation. When food choice is examined in a context that does not explicitly focus attention on food labels, the influence of messages promoting better nutrition on food labels is not always observed [6].

Food labels are crowded with information and messages, and the level of trust that a consumer has for the information influences how they will respond to it [7]. The less a labelling element is trusted, the less likely it is to influence purchasing decisions.

The need for better food choices to achieve better health outcome in Australia is apparent. In the most recent national dietary survey conducted in 2011-12, more than a third of food energy (38.5\% in children, $34.6 \%$ in adults) was from foods that are not recommended for health, which are called discretionary foods [8].

In Australia, a Health Star Rating (HSR) system was introduced in June 2014. This is a voluntary front-of-pack labelling system to rank the nutritional profile of packaged foods within a food category and is based on a scale of a half a star to 5 stars [9]. In January 2013, regulations allowing a broad range of health claims on food labels were introduced, with a 3 year period of grace for food businesses to comply with the new requirements [10]. In this changing context, consumer attitudes to the various labelling elements that guide their purchasing behaviour and thereby dietary intake are relevant and important for food manufacturers, health practitioners, and government regulators alike. 
In 2011, the population of South Australia was almost 1.6 million with $77 \%$ living in the capital city, Adelaide. This study used a long standing, annual survey of South Australians aged 15 years and older. The South Australian Health Omnibus Survey [11] is a shared cost survey of the South Australian community that has been conducted each spring by a private company since 1991. The aim of this study was to investigate the extent to which adults trust messages on food labels about health and nutrient content, and the extent to which they believe they use the information to guide their food purchase.

\section{METHODS:}

Questions relating to food labels (Table 1) were developed by the investigators and included in the 2015 South Australian Health Omnibus Survey.

Table 1. Survey questions and response formats

\begin{tabular}{|c|c|}
\hline Statement/question & Response categories \\
\hline $\begin{array}{l}\text { Statements about health on food packaging } \\
\text { are a trustworthy source of information. }\end{array}$ & $\begin{array}{l}\text { Agree completely } \\
\text { Agree somewhat } \\
\text { Disagree somewhat } \\
\text { Disagree completely } \\
\text { Don't know }\end{array}$ \\
\hline $\begin{array}{l}\text { The Nutrient Information Panel (NIP) on food } \\
\text { packaging is a trustworthy source of } \\
\text { information. (Picture of NIP shown) }\end{array}$ & $\begin{array}{l}\text { Agree completely } \\
\text { Agree somewhat } \\
\text { Disagree somewhat } \\
\text { Disagree completely } \\
\text { Don't know }\end{array}$ \\
\hline $\begin{array}{l}\text { Which of the following on a food package do } \\
\text { you use to guide your decision to purchase a } \\
\text { new breakfast cereal? }\end{array}$ & $\begin{array}{l}\text { (please choose any that apply) } \\
\text { 1. A statement on the front of the pack about how the food } \\
\text { effects health. } \\
\text { 2. The statement on the back of the pack about nutrient } \\
\text { content (the Nutrition Information Panel). } \\
\text { 3. The health star rating on the front of the pack. } \\
\text { 4. None of the above } \\
\text { 5. I don't use information on food packaging } \\
\text { 6. I don't buy breakfast cereal } \\
\text { 7. Don't know } \\
\text { 8. Refused }\end{array}$ \\
\hline $\begin{array}{l}\text { In general, how would you rate your dietary } \\
\text { intake? }\end{array}$ & $\begin{array}{l}\text { Extremely unhealthy } \\
\text { Unhealthy } \\
\text { Neither healthy nor unhealthy } \\
\text { Healthy } \\
\text { Extremely healthy }\end{array}$ \\
\hline $\begin{array}{l}\text { Leaving aside the price, what is the most } \\
\text { important information that you look for on a } \\
\text { food label when you are buying a food for the } \\
\text { first time? }\end{array}$ & $\begin{array}{l}\text { 1. Country of origin } \\
\text { 2. Claims about nutrition (eg fat content, fibre content) } \\
\text { 3. Claims about health (eg good for bones, lowers } \\
\text { cholesterol) } \\
\text { 4. Ingredient list } \\
\text { 5. Don't look at labels } \\
\text { 6. Other } \\
\text { 7. Don't know } \\
\text { 8. Refused }\end{array}$ \\
\hline
\end{tabular}

The 2015 Spring Health Omnibus survey was administered face-to-face with 3005 people between September 2015 and December 2015. A random stratified sampling technique was used 
for subject selection, with subjects aged 15 years or over being eligible. Households were selected from Statistical Area Level 1 (SA1s) which is the smallest geography for which detailed census information is released. For the metropolitan sample, 398 SA1s used in the 2011 census were selected with a probability proportional to their size. For the rural area sample, all towns with a population size of 10,000 or greater in the 2011 census were selected automatically, and the balance of the 132 SA1 sample randomly selected from centres with a population of 1000 or more with a probability proportional to size. For each of the 500 SA1s, a starting point was randomly selected, followed by a 'skip' pattern to choose 10 dwellings. Only one interview was conducted per household - where more than one person in the household was 15 years of age or over, the respondent was the person with the most recent birthday. Demographic information collected included the participants age in years, gender, and area of residence categorised as metropolitan or rural.

The questionnaire and the survey methodology were approved by the Human Research Ethics committee of the University of Adelaide. All participants gave verbal informed consent, and continued participation in the face-to-face interview was taken as evidence of continued willingness to participate.

\section{Statistical analysis:}

Results were weighted to the age, sex, and area of residence structure of the South Australian adult population.

Association of age group (15-34 years, 35-54 years, 55 years and older), sex, and area of residence (metropolitan or rural) with the single response survey questions were assessed using chi square tests after eliminating the 'Don't know' responses. Where multiple responses could be chosen, logistic regression was used to simultaneously assess the association of age (as a continuous variable), sex, and area of residence with each response independently. One way ANOVA was used to examine the association of age, sex, and area of residence with response to the question on what was the most important information to look for on a food label when buying a food for the first time.

The criteria for statistical significance was taken as $p<0.05$. Analysis was conducted using IBM SPSS for Windows Version 20 (SPSS, Inc., Chicago, IL)

\section{RESULTS}

The response rate for the survey (i.e.the number of completed interviews as a percentage of the initial eligible sample) was $57.3 \%$ and the participation rate (i.e. the number of completed interviews as a percentage of the initial eligible sample reduced by those who could not be contacted after 6 contact attempts) was $66.1 \%$. The survey sample was 1816 women, and 1189 men; with 626 aged 15-34 years; 850 aged 35-54 yrs; and 1529 aged above 55 years. Respondents living in the metropolitan area numbered 2120, with 885 living in a rural area.

Most of the respondents agreed with the statement that 'The Nutrient Information Panel (NIP) on food packaging is a trustworthy source of information' $72.5 \%$ agreed somewhat or agreed completely). There was a much lower agreement with the analogous phrase 'Statements about health on food packaging are a trustworthy source of information'; $41.6 \%$ agreed somewhat or agreed completely (Figure 1). A small percentage of respondents $(5.1 \%$ for 
'statements about health' and 6.7\% for the NIP) gave a response other than an assessment of agreement, with most being 'I don't know'. The responses differed significantly by age group, sex, and area of residence for both statements with older people less likely to agree with the statements (67.3\% aged 55 years and above agreed completely or agreed somewhat, compared to $80.0 \%$ aged $35-54$ years, and $83.2 \%$ aged $15-34$ years, ChiSq $=108.7, \mathrm{df}=6, \mathrm{p}<0.001$ for the NIP statement; $37.2 \%$ aged 55 years and above agreed completely or agreed somewhat, compared to $43.5 \%$ aged 35-54 years, and 50.4\% aged 15-34 years, ChiSq=50.7, $\mathrm{df}=6, \mathrm{p}<0.001$ for the statement about health on food packaging). Men were significantly more likely to respond that information on labelling was trustworthy $(77.1 \%$ of men agreed completely or agreed somewhat compared to $76.2 \%$ of women, ChiSq $=10.1$, df $3, p=0.018$ for the NIP statement; $46.8 \%$ of men agreed completely or agreed somewhat compared to $40.5 \%$ of women, ChiSq=18.9, df $=3$, $\mathrm{p}<0.001$ for the statement about health on food packaging). Respondents from a rural area were less likely to agree with each statement than respondents from a metropolitan area $(71.0 \%$ of rural residents agreed completey or agreed somewhat compared to $78.5 \%$ of metropolitan residents, ChiSq=61.1, $\mathrm{df}=3, \mathrm{p}<0.001$ for the NIP statement; $41.9 \%$ of rural residents agreed completely or agreed somewhat compared to $44.1 \%$ of metropolitan residents, $\mathrm{ChiSq}=16.0, \mathrm{df}=3$, $\mathrm{p}=0.001$ for the statement about health on food packaging).

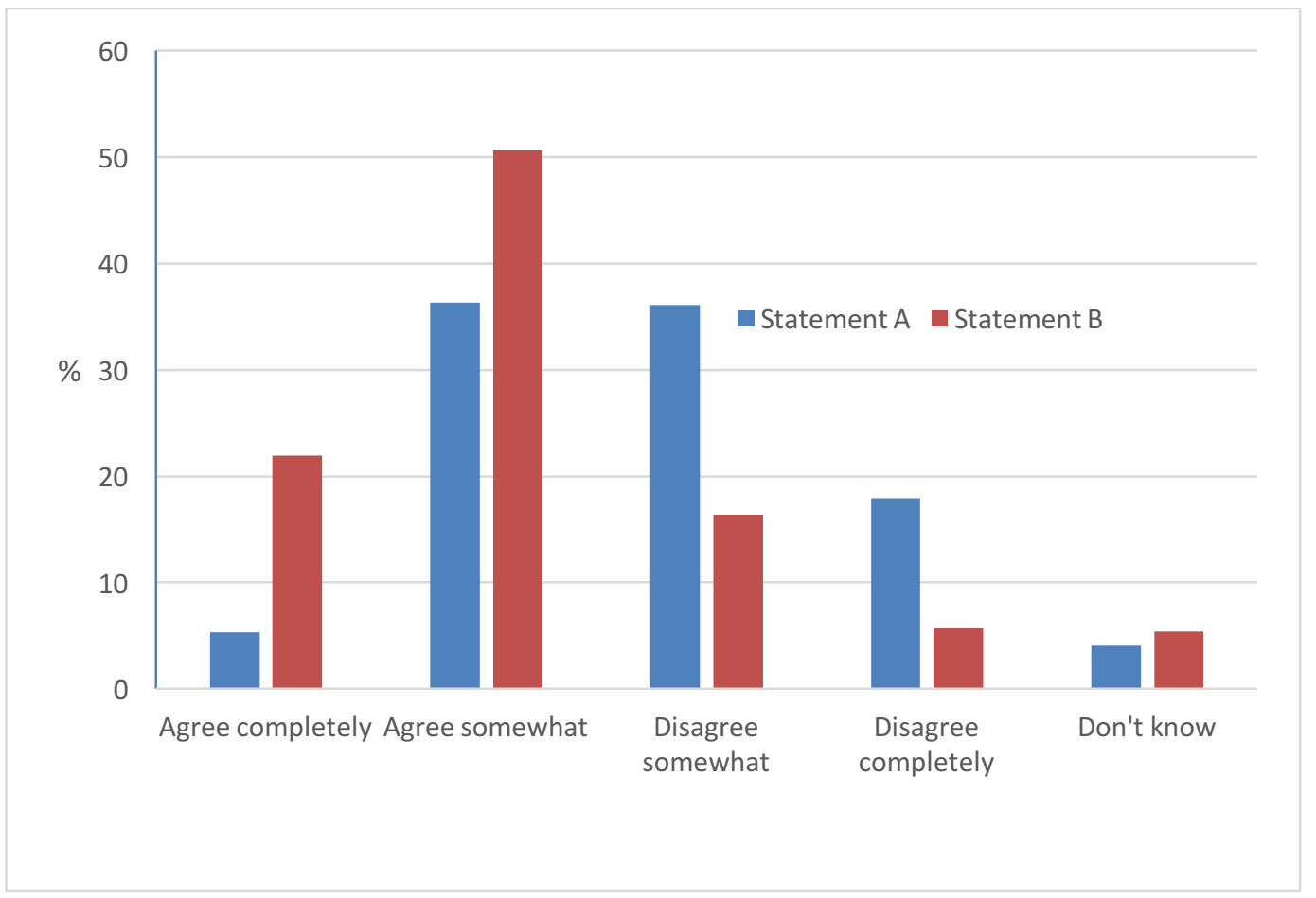

Figure 1. Trust in food label statements about health and nutrition content. Survey response to questions about trust in statements on food labels about health and nutrient content.

Statement A: Statements about health on food packaging are a trustworthy source of information. Statement B: The Nutrient Information Panel (NIP) is a trustworthy source of information.

Most respondents $(70.6 \%)$ rated the healthiness of their dietary intake as 'healthy' or 'extremely healthy.' Only $0.3 \%$ of respondents responded that they 'did not know' or declined to 
answer this question. Self-assessed healthiness of dietary intake was strongly associated with age; older people were more likely to rate their diet as healthier $(81.1 \%$ of people aged 55 years and above rated their diet as healthy or extremely healthy compared to $71.1 \%$ of people aged 35 54 years and $59.1 \%$ of people aged 15-34 years, $\mathrm{ChiSq}=153.5, \mathrm{p}<0.001$ ) (Figure 2). Women were more likely than men to rate their dietary intake as healthier $(72.5 \%$ of women rated their diet as healthy or extremely healthy compared to $69.1 \%$ of men, $\mathrm{ChiSq}=10.6, \mathrm{p}=0.03$ ). People from rural areas were less likely than people from metropolitan areas to rate their dietary intake as healthy $(66.9 \%$ of people from rural areas rated their diet as healthy or extremely healthy compared to $72.1 \%$ of people from metropolitan areas, ChiSq=12.3, $\mathrm{p}=0.015$ ).

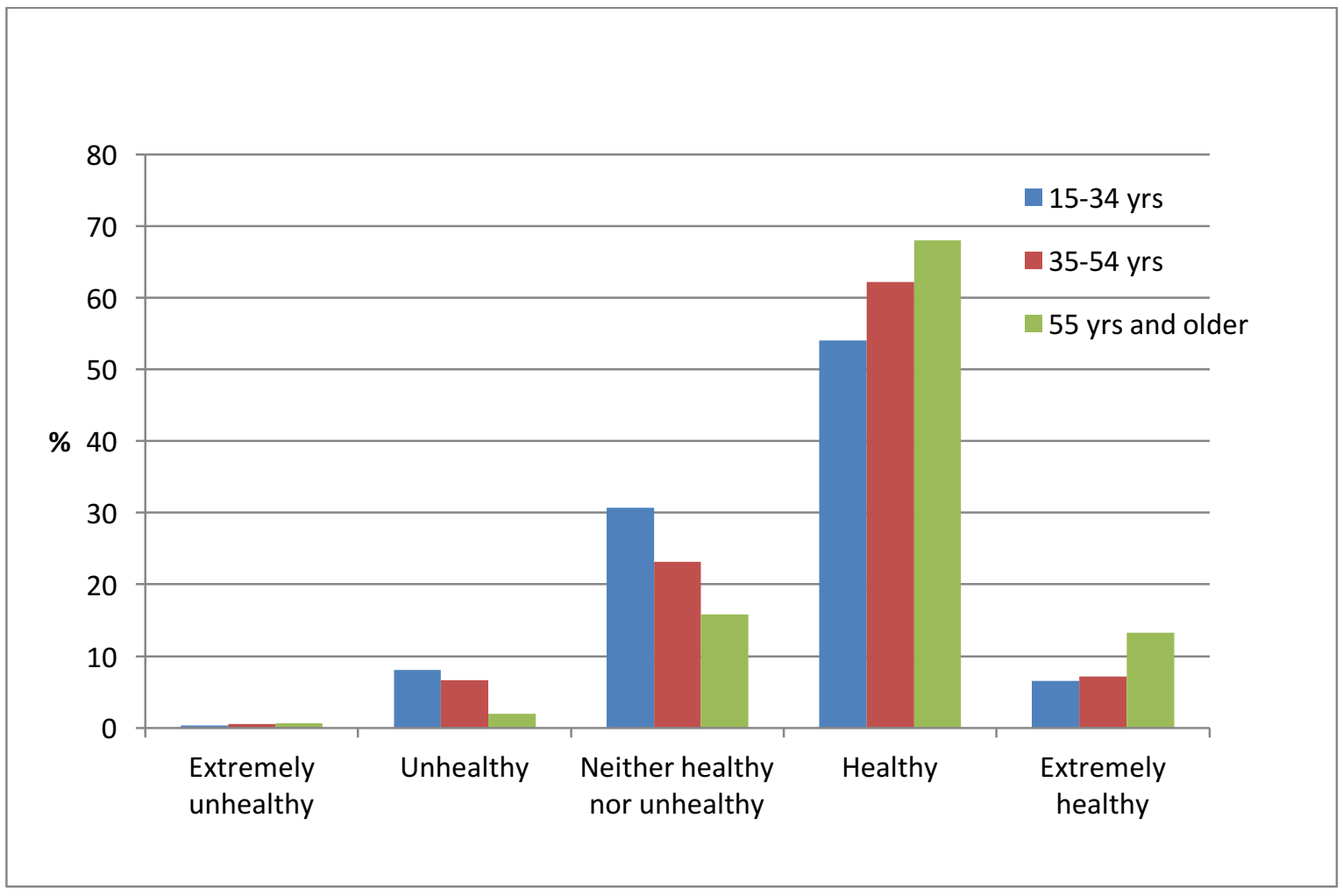

Figure 2. Self-rating of dietary intake. Survey response by age category to the question 'In general, how would you rate your dietary intake?'

The responses to the question about using aspects of food packaging to guide selection of a new breakfast cereal and analysis of factors associated with responses are summarized in Table 2. More than half of the respondents stated that they would use the NIP to help guide their decision about purchase of a new breakfast cereal. Older people were less likely to select this response. Women and people living in rural areas were more likely to select this response. People who reported that they were having a healthy or extremely healthy dietary intake were more likely to say they would use the NIP, while people who reported they were having an unhealthy or extremely unhealthy diet were less likely to report they would use the NIP. A small percentage $(15.2 \%)$ of respondents said they would use the HSR on the front of the pack to help guide their decision about a new breakfast cereal. Women were more likely to choose this 
response than men, and people living in metropolitan areas were more likely to choose this response than people living in rural areas.

Table 2. Factors associated with the response for food label information to guide purchase of a new breakfast cereal.

\begin{tabular}{|c|c|c|}
\hline Response category & $\begin{array}{l}\text { Weighted } \\
\text { response } \\
\%^{\dagger}(\mathrm{n})\end{array}$ & $\begin{array}{l}\text { Significantly associated variables } \\
(\beta, p)^{*}\end{array}$ \\
\hline $\begin{array}{l}\text { A statement on the front of the pack about } \\
\text { how the food effects health. }\end{array}$ & $8.9 \%(266)$ & $\begin{array}{l}\text { Age }(-0.010,0.002) \\
\text { Metro/rural }(-0.429,0.007)\end{array}$ \\
\hline $\begin{array}{l}\text { The statement on the back of the pack about } \\
\text { the nutrient content (Nutrition Information } \\
\text { Panel) }\end{array}$ & $\begin{array}{l}50.8 \% \\
(1525)\end{array}$ & $\begin{array}{l}\text { Age }(-0.008,<0.001) \\
\text { Sex }(0.503,<0.001) \\
\text { Metro/rural }(0.204,0.018) \\
\text { Diet rated healthy }(0.385,<0.001) \\
\text { Diet rated unhealthy }(-0.374,0.036)\end{array}$ \\
\hline $\begin{array}{l}\text { The Health Star Rating on the front of the } \\
\text { pack }\end{array}$ & $\begin{array}{c}15.2 \% \\
(455)\end{array}$ & $\begin{array}{l}\operatorname{Sex}(0.404,<0.001) \\
\text { Metro/rural }(-0.341,0.008)\end{array}$ \\
\hline None of the above & $7.9 \%(237)$ & $\begin{array}{l}\text { Age }(0.016,<0.001) \\
\text { Diet rated unhealthy }(0.626,0.049)\end{array}$ \\
\hline I don't use information on food packaging & $\begin{array}{l}14.2 \% \\
(424)\end{array}$ & $\begin{array}{l}\text { Age }(0.012,<0.001) \\
\text { Sex }(-0.484,<0.001) \\
\text { Metro/rural }(0.349,0.003) \\
\text { Diet rated healthy }(-0.455,<0.001) \\
\text { Diet rated unhealthy } 0.755,<0.001)\end{array}$ \\
\hline I don't buy breakfast cereal & $\begin{array}{c}14.7 \% \\
(441)\end{array}$ & $\begin{array}{l}\operatorname{Sex}(-0.603,<0.001) \\
\text { Metro/rural }(-0.367,0.003)\end{array}$ \\
\hline Don’t know & $\begin{array}{c}0.9 \% \\
(28)\end{array}$ & [Regression not conducted] \\
\hline Refused to respond & $\begin{array}{l}0.1 \% \\
(2)\end{array}$ & [Regression not conducted] \\
\hline
\end{tabular}

*A logistic regression model was run on each response with independent variables including age (in years), sex, metropolitan or rural area of residence, self rating of dietary intake as extremely healthy or healthy, self-rating of dietary intake as extremely unhealthy or unhealthy.

$\dagger$ Multiple responses were allowed so percentages do not add to $100 \%$.

The least frequently chosen response to help guide a decision about a new breakfast cereal was the use of a statement about how the food effects health (8.9\%). Once again, older people were less likely to select this response, while people living in metropolitan areas were more likely to choose this response compared to people living in rural areas. Eight percent of the 
sample stated that they used none of the listed options when choosing a new breakfast cereal, and this response was more likely to be selected by people who were older, and by people who rated their dietary intake as unhealthy or extremely unhealthy. A substantial sized group (14.2\%) reported that they did not use information on food packaging to help guide their food choice these people were more likely to be older, male, lived in a rural area, and more likely to have rated their dietary intake as unhealthy or extremely unhealthy. Finally, another group (14.7\%) does not buy breakfast cereal, and these people were more likely to be male and more likely to live in the metropolitan areas.

The response to the question about what information on a food label, besides price, would be used when buying a food for the first time is shown by age category in Figure 3. Only one response was allowed. The most frequent response was 'country of origin' (35.0\% of subjects), followed by the ingredient list (21.6\%) and claims about nutrition (20.9\%). Claims about health accounted for $4.6 \%$ of responses while $14.3 \%$ stated that they didn't look at labels.

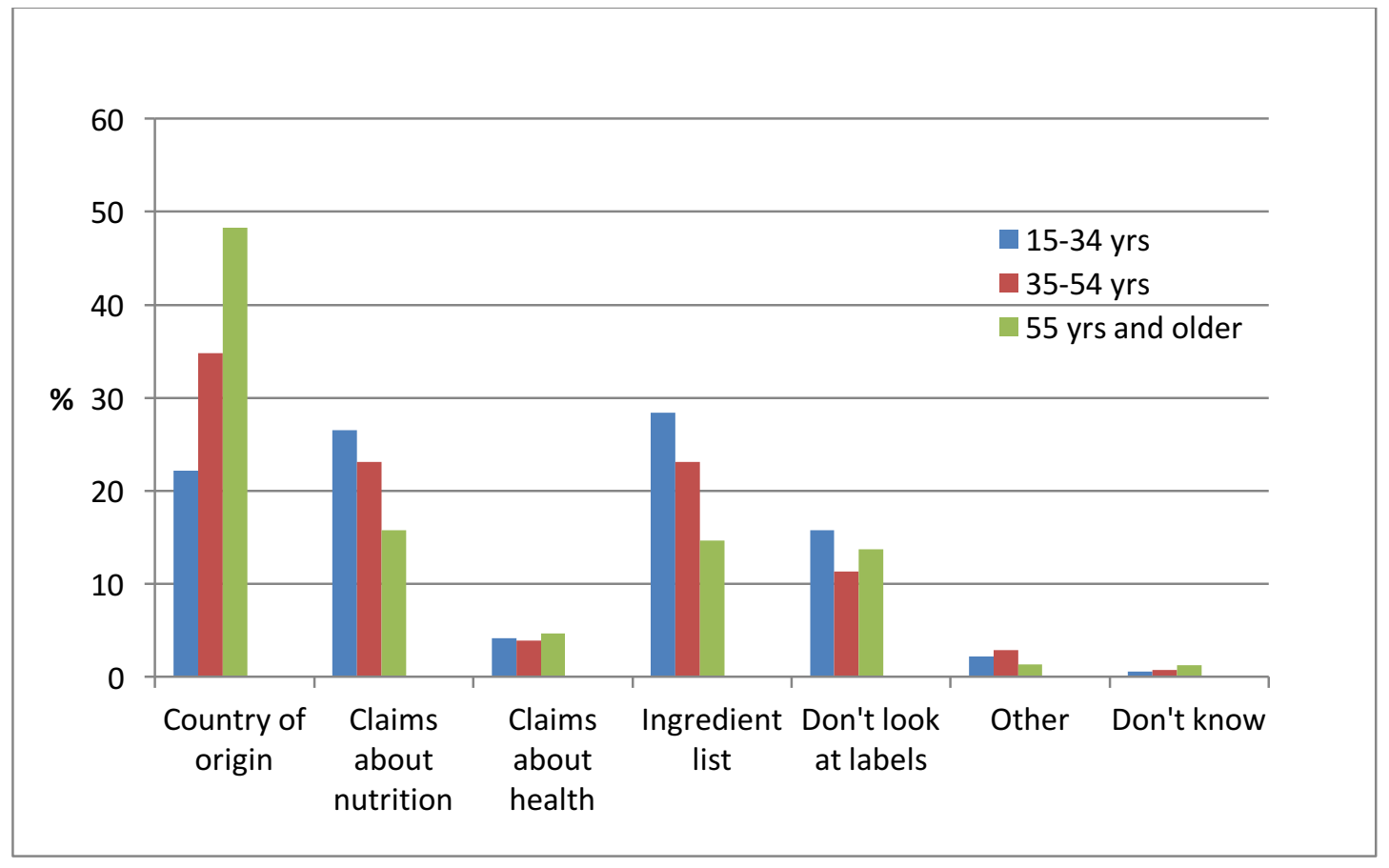

Figure 3. The most important food label information when buying a food for the first time. Survey response by age category to a question about the most important information on a food label when buying a food for the first time

There was a significant difference in mean age across response categories $(\mathrm{F}=46.9, \mathrm{df}=4$, $\mathrm{p}<0.001$ ) with older people more likely than others to look for country of origin, and less likely to look for claims about nutrition or the ingredient list. The ratio of men to women also differed significantly across the response categories $(\mathrm{F}=11.7, \mathrm{df}=4, \mathrm{p}<0.001)$ with men more likely to respond that they didn't look at labels. Finally, area of residence differed significantly across categories $(\mathrm{F}=16.1, \mathrm{df}=4, \mathrm{p}<0.001)$ with metropolitan residents over-represented in selecting the 
ingredient list and claims about health as the most important information to look for on a food label, besides price, when buying a new food for the first time.

\section{DISCUSSION}

South Australian adults who responded to this survey demonstrated a greater level of trust in the content of the NIP than in health claims on food packaging. Studies in Europe, the United States, and Australia [4, 12, 13] have demonstrated that consumers have more confidence in elements of the food label that are regulated [13]. In Australia, the NIP is required on all packaged foods except those in very small packages. The NIP is provided in a standard format, with regulation regarding content and presentation. Health claims are a more recent introduction. Despite having a high degree of regulation, use of health claims are voluntary (hence less common), and the format and wording are not standardized. These factors may contribute to consumers believing health claims to be unregulated and thereby creating a perception that the messaging is developed by marketers for the purpose of selling the food, rather than the benefit of consumers. Further research is needed to investigate whether knowledge of regulation will enhance consumer trust in health claims and whether the standardized appearance of health claims, similar to the NIP, would enhance the perception that health claims are regulated and therefore trustworthy.

A recent systematic review of trust in food labelling [7] highlighted that trust in the messenger is important to enable trust in the message that is delivered. The information on a food label may be required by the government or placed at the discretion of the company, for example. The level of trust in a message has an impact on how the message is received, and what action is taken as a result. While many studies have examined consumer comprehension and preference regarding front-of-pack nutrition labels [eg 1, 2, 3, 5], few studies have examined the impact on behaviour. One study conducted on university students in New Zealand [14] found that each of the front-of-pack labels tested led to significantly positive changes in purchase intention regardless of label type, size, or the nutritional quality of the food product carrying the label. A later study conducted in New Zealand on consumers recruited on exit from supermarkets by the same investigators [15] found that a HSR label decreased intention to purchase regardless of whether the product carried 5 stars or 2 stars. The investigators did not speculate on the reason for the decreased preference, but noted that failure to differentiate between the ratings indicated a failure of the system. A UK study examined supermarket sales data four weeks before and after the introduction of an interpretive front-of-pack nutrition label for two food categories (chilled packaged meals and fresh packaged sandwiches) [16]. They found that the introduction of the label element did not influence the sale of healthier products. The investigators found that in German adults [3], front-of-pack labels were able to assist with identifying healthier food but did not influence envisaged daily food consumption. Changing consumer behaviour to a healthier dietary intake will require more than the ability to identify healthier food from the packaging.

Consistent with the finding regarding trustworthiness, the NIP was chosen by a much higher percentage of respondents $(51 \%)$ than those who chose a health claim statement $(9 \%)$ or a HSR $(15 \%)$ in response to a hypothetical question about information to guide the purchase of a new breakfast cereal. However, $8 \%$ of respondents said they would not use any of the three label elements and $14 \%$ stated that they did not use any information on food packaging. Interestingly, 
people who don't use information on food packaging to guide a purchase decision on a new breakfast cereal are significantly more likely to be older, male, living in the country, and more likely to rate their dietary intake as unhealthy. The final survey question also returned $14 \%$ of people stating they did not use food labels, providing internal consistency for this measure in the survey. It is a common finding that women are more likey to use food labels [17].

Age was an important modifier of attitudes towards food labels for adults in South Australia. Older people were less likely to trust health-food statements on labels or the NIP. They were also less likely than younger people to use this information to choose a new breakfast cereal. This may reflect a higher level of confidence in their own understanding of healthy foods - there was also a strong trend with age towards a self-assessed healthier dietary intake.

The large percentage of adults who rated their own diet as healthy or very healthy is not consistent with the high prevalence of overweight and obesity in Australian adults (61\% in 201112) [8], or the high intake of discretionary foods which generally contain excessive amounts of fat, added sugar, and or salt [8]. It is a matter of conjecture how people self-assess the healthiness of their total dietary intake, and this may be an insightful area of investigation. However the relatively positive distribution of responses is at odds with the high intake of non-recommended foods and the high prevalence of overweight and obesity.

People who use the NIP to guide their decision to buy a new breakfast cereal were more likely to rate their dietary intake as healthy. Furthermore, people who reported that they don't use food labels, or would not use any of the health or nutrition information provided, were more likely to rate their dietary intake as unhealthy. Although actual dietary intake wasn't measured, it seems reasonable that people who are committed or aspire to a healthy dietary intake are more likely to be interested in the nutrient content of the packaged food they eat, and actively seek such information.

It is possible that the preferred information used to guide the decision to purchase a new breakfast cereal is different from other foods. There is a suggestion that nutritional information is not used in the decision process for familiar packaged foods [6], because these foods are favoured specifically for the reason that they are familiar, and is rarely considered in choosing discretionary food [1] or special occasion food [6] because these foods are for purposes other than nutrition. Future research could explore the variation in response to different food categories and different eating occasions. It is likely that people may have different general and nutritional interests in different types of food.

The Australian Government's Health Star Rating system was introduced in 2015. A recent report [18] found that over 3000 products now carry the HSR. The relatively low prevalence of survey respondents who stated they would use the HSR to assist in the selection of a new breakfast cereal more likely reflects the relatively recent introduction of this system and could be expected to increase as it becomes more widely promoted by the Australian government and the food industry

A key purpose of the HSR system is to incentivise reformulation of food products so that they gain a higher HSR (http://healthstarrating.gov.au/). Others have given examples of the likely public health benefit of food reformulation in New Zealand, the US and the Netherlands. They have demonstrated that an interpretive food labelling system may have a health benefit even if it does not have a significant impact on consumer behaviour [11]. Reformulation for this 
purpose is likely to focus on the nutrients which contribute to the HSR - in this case saturated fat, salt, and sugar, along with credit for substantial content of fruits, vegeables, and nuts.

Country of origin was the most important information, besides price, that South Australian adults would look for on a food label when choosing a new food. Interest in country of origin of a food is understood to be a preference of consumers for foods produced in their own country $[19,20]$, following either from inferences about food quality and safety, or a belief that locally produced foods are better for the local economy. The ranking of important issues on food labels is not consistent across countries [17]. For example, in Ghana the expiration date is ranked first, followed by nutritional information and the ingredient list, with country of origin being ranked as relatively unimportant [21].

Older people were more likely to identify 'country of origin' as the most important label element and less likely to identify a statement about health or the ingredient list. This is consistent with the hypothesis that older people are more confident about the health qualities of the food they buy, and therefore more interested in other elements of the label. For the youngest age group, the element of most interest was the ingredient list followed by statements about the nutrient content before country of origin. It is not known whether examination of the ingredient list was to look for the presence of particular ingredients, or their absence (for example, in order to avoid particular ingredients). This is an issue worthy of further investigation. A claim about health was poorly supported as the most important element of the label besides price (only $5 \%$ of subjects), which may be related to a lack of trust in the message, or a confidence that knowledge of what is in the food (ingredients or nutrients) will allow sufficient inference of its benefits.

When Australian and New Zealand shoppers $(n=160)$ were observed reading a food label and questioned about the information they had read [22], only $1 \%$ stated they had read the country of origin information, while $36 \%$ said they had read the ingredients list and $34 \%$ that they had read the NIP. The largest percentage $(58 \%)$ said they had read the product/brand/flavour name. While this is not directly comparable to a question to all people on what would be the most important label element for them when examining a new food, it is nevertheless striking that among people actually reading a label, it is very uncommon for them to recall reading the country of origin.

The strength of this research is that it arises from a population based survey of South Australians. The results are prevalence estimates of the attitudes and perceptions of South Australian adults during a time of change to some aspects of the Australian food labelling system. However, the results arise from subjects answering short questions - it is not clear how the attitudes and perceptions expressed in this survey translate into purchase or consumption behaviour. In particular, there is no assurance that trust in messages on food packaging influences consumption behaviour.

\section{CONCLUSION}

South Australians adults have less trust in statements about the health benefits of food on labels than they do for information from the NIP, even though both elements are subject to a high degree of regulation. Consumer trust in health claims may be improved by promoting the regulatory requirements that need to be met prior to using a health claim on a food label. There were considerable differences in responses across age groups. For example, younger adults 
(particularly females) and those who self-ranked their diet as healthy used and trusted food label information the most. Older respondents, particularly males and those who self-ranked their diet as unhealthy, were less likely to use or trust various elements of a food label. Admittedly, South Australian adults have an unrealistically high assessment of how healthy their dietary intake is. For an unfamiliar food, South Australian adults considered that apart from price, country of origin is an especially important element on food packaging.

Abbreviations: Nutrition Information Panel (NIP), Health Star Rating (HSR), Commonwealth Scientific and Industrial Research Organisation (CSIRO)

Competing interests: The authors declare that they have no competing interests.

Authors' contributions: Malcolm Riley DipNutrDiet PhD conceived the study, developed the questions, undertook the analysis and drafted the manuscript. Jane Bowen $\mathrm{PhD}$ assisted in interpretation of the results and reviewed the manuscript. Debra Krause assisted in interpretation of the results and reviewed the manuscript. Darren Jones assisted in interpretation of the results and reviewed the manuscript. Welma Stonehouse $\mathrm{PhD}$ assisted in drafting of the questions, interpretation of the results and reviewed the manuscript.

Acknowledgement and Funding: Funding for this project was provided by the CSIRO - the Australian Government Science Organisation.

\section{REFERENCES:}

1. Talati Z, Pettigrew S, Kelly B, Ball K, Dixon H, Shilton T. Consumers' response to front-of- pack labels that vary by interpretive content. Appetite 2016;101:205-213.

2. Kelly B, Hughes C, Chapman K, Louie JC, Dixon H, Crawford J, King L, Daube M, Slevin T. Consumer testing of the acceptability and effectiveness of front-of-pack food labelling systems for the Australian grocery market. Health Promotion International 2009;24:120

3. Borgmeier I, Westenhoefer J. Impact of different food label formats on healthiness evaluation and food choice of consumers: a randomized-controlled study. BMC Public Health 2009;9:184

4. Gracia A, de-Magistris T. Consumer preferences for food labelling: What ranks first? Food Control 2016;61:31-46.

5. Watson WL, Kelly B, Hector D, Hughes C, King L, Crawford J, Sergeant J, Chapman K. Can front-of-pack labelling schemes guide healthier food choices? Australian shoppers' responses to seven labelling formats. Appetite 2014;72:90-97.

6. Wahlich C, Gardner B, McGowan L. How, when and why do young women use nutrition information on food labels? A qualitative analysis. Psychology and Health 2013;28:202-216.

7. Tonkin E, Wilson AM, Coveney J, Webb T, Meyer SB. Trust in and through labelling a systematic review and critique. Br Food Journal 2015,117:318-338. 
8. Australian Bureau of Statistics (2014). Australian Health Survey: Nutrition First Results - Foods and Nutrients, 2011-12. Cat No 4364.0.55.007.

9. Health Star Rating System [http://healthstarrating.gov.au/internet/healthstarrating/publishing.nsf/Content/Abouthealth-stars] accessed on September 4th 2016.

10. Food Standards Australia New Zealand [http://www.foodstandards.gov.au/consumer/labelling/nutrition/pages/healthclaimsstand ard5081.aspx] accessed on Sept 4th 2016.

11. Health Omnibus Survey [https://health.adelaide.edu.au/pros/data/hos/] accessed Sept 4th 2016

12. Hawley KL, Roberto CA, Bragg MA, Liu PJ, Swartz MB, Brownell KD. The science on front-of-package food labels. Public Health Nutrition 2012;16:430-439.

13. Tonkin E, Webb T, Coveney J, Meyer SB, Wilson AM. Consumer trust in the Australian food system - the everyday erosive impact of food labelling. Appetite 2016;103:118127.

14. Hamlin RP, McNeill LS, Moore V. The impact of front-of-pack nutrition labels on consumer product evaluation and choice: an experiemental study. Public Health Nutrition 2014;18:2126-2134.

15. Hamlin RP, McNeill LS. Does the Australasian 'Health Star Rating' front of pack nutritional label system work? Nutrients 2016, 8, 327; doi:10.3390/nu8060327

16. Sacks G, Rayner M, Swinburn B. Impact of front-of-pack 'traffic-light' nutrition labelling on consumer food purchases in the UK. Health Promotion International 2009;24:344-352.

17. Mandle J, Tugendhaft A, Michalow J, Hofman K. Nutrition labelling: a review of research on consumer and industry response in the global South. Glob Health Action 2015;8:25912 [http://dx.doi.org/10.3402/gha.v8.25912]

18. Annison G. The Health Star Rating - setting the record straight. Food Australia 2016;68:20-21.

19. Berry C, Mukherjee A, Burton S, Howlett E. A COOL effect: The direct and indirect impact of country-of-origin disclosures on purchase intentions for retail food products. $\mathrm{J}$ retailing 2015;91:533-542.

20. Xie J, Gao Z, Swisher M, Zhao X. Consumers' preferences for fresh broccolis: interactive effects between country of origin and organic labels. Agricultural Economics 2016;47:181-191.

21. Ababio PF, Adi DD, Amoah M. Evaluating the awareness and importance of food labelling information among consumers in the Kumasi metropolis of Ghana. Food Control 2012;26:571-4.

22. Colmar Brunton Social Research (2007). Consumer Use of Nutrition Content Claims in Shopping Environments. Research report prepared for Food Standards Australia New Zealand.

[http://www.foodstandards.gov.au/consumer/labelling/nutrition/pages/researchworkonnu trit3081.aspx] Accessed on Sept 6th 2016. 